\title{
BUILDING BRIDGES: BRINGING NONFORMAL PEDAGOGIES INTO THE CLASSROOM
}

\author{
Maya Wizel \\ Middlebury College (USA) \\ Bar-Ilan University (Israel)
}

\begin{abstract}
Education systems worldwide have long sought ways to engage and support learners to become self-directed and develop 21 st-century skills. This became even more relevant-and crucial-with the COVID-19 pandemic restrictions. Solutions to help formal education systems establish innovative pedagogies and methods to organize learning can be found in places as unpredictable as nonformal education settings. In this study, I interviewed educators with backgrounds in nonformal education to better understand that system's qualities and how they can be transferred into formal settings. Findings regarding practices include teachers prioritizing instructional choice (voluntarism); addressing social-emotional aspects through diverse teaching methods that emphasize students' active learning and real-life experiences (classroom as a social group); and excelling in dialogue and teamwork to sustain solid interpersonal relationships with students and colleagues (relationships and dialogue). Educators working in nonformal settings often know they have a unique collection of difficult-to-articulate abilities. This research presents the voices of youth movement leaders in Israel, who nonformally have been doing what formal educators worldwide are trying to figure out; defines some of their skills; and explores how those skills can be applied in formal settings. This study has been published as a book in Hebrew in 2020. This paper embodies a few aspects of the study and will benefit formal education leaders and practitioners who seek to incorporate methods from nonformal pedagogies.
\end{abstract}

Keywords: Choice, educational change, nonformal pedagogies, youth movement, teaching.

\section{Introduction}

\subsection{1st-century education challenges}

In the past two decades, there has been continuous worldwide conversation regarding the future of public education systems. One of the leading terms discussed is 21st-century competencies (Organization for Economic Co-operation and Development, 2018), which encompasses the education system's need to help students develop the knowledge, skills, values, and attitudes, including personal, social, and global perspectives, needed in this century. These recommended skills relate to citizenship, being part of the workforce, and living in a world that is digital and continually changing. Relevant skills include adaptiveness and flexibility, creative thinking, teamwork, communication, critical thinking, and social awareness. In considering this broad range of recommendations and the challenges that education systems face worldwide, it becomes clear that some answers do not need to be reinvented. They can simply be adopted from nonformal education systems that have succeeded in those areas for decades. This sort of nonformal education has received far less attention from academic researchers than has its formal counterpart (Cohen, 2015). The aim of this research is to enhance awareness of this often-overlooked source of relevant and inspiring educational practices.

\subsection{Distinction between formal and nonformal education}

The literature uses various terms used to describe and distinguish educational activities that occur inside and outside of schools. Smith (2002) and Silberman-Keller (2003) termed the lifelong learning and development of values, knowledge, and skills as informal education. This sort of learning comes with exposure to experiences within the family or environment, for example, learning through play or from day-to-day life experiences. Nonformal education refers to an organized system of learning and development with specific goals and methodologies, such as community sports teams or music bands. Juxtaposed with those definitions are ones that use an organizational framework and others that emphasize educational aspects, such as pedagogy (Shmida \& Romi, 2008). Although these definitions offer some framework for nonformal education, other scholars suggested that any attempt to define nonformal 
education contradicts the essence of this type of education, which is characterized by flexibility and diversity. It is impossible and even not worthy to contain it to one narrowing definition (Smith, 2002). In this paper, I use the term nonformal education and nonformal pedagogies to describe types of practices common in youth movements.

Silberman-Keller (2003) focused on how learning and teaching happen in nonformal education settings. According to her, nonformal pedagogy relates to the participants' background, and learning is "situated"-it happens while experiencing social and cultural activities and will change accordingly. She also described nonformal learning as related to dialogue and conversation; thus, it is less expected and predicted. Kahane (1997), an Israeli researcher who unpacked the qualities of nonformal education, made significant contributions to the concept and to the field overall. Decades of field research led Kahane to create a set of eight structural components of informality, each representing a distinct aspect of the concept. He named the structural components, defined them, and described the effects each could be expected to have on participants' worldviews, social behaviors, and interactions among the group (Cohen, 2015, p. 224). In the following sections, I explain those components relevant to this paper: voluntarism, multiplicity, and symmetry. Although I offer some definitions and distinctions between nonformal and formal education, some scholars describe educational activities as more of a line, or a bridge, than as two sides of a wall (Michaeli, 2013; Smith, 2002).

\subsection{Nonformal educators}

Most Israeli children join a youth movement (similar to a youth club or camp in the United States), attend at least two activities per week, and build strong social ties that extend far beyond the confines of formal programming. "Youth movements can play an important role in adolescents' process of identity development, offering a venue for experimentation and exploration of new roles, ideas, and values" (Cohen, 2015 , p. 225). Teens take active roles as counselors in the many youth movements in Israel. They volunteer in educational settings that are distinctly different from schools-nonformal educational settings using nonformal pedagogies. The leaders of such organizations carry roles with unique and complex responsibilities that require varying organizational and pedagogical skills. Through this role, some leaders find their passion for education, complete their certifications, and enter the formal education system as classroom teachers and school principals.

Internationally, some educators in the formal Kindergarten-through-12th-grade $(\mathrm{K}-12)$ system, have backgrounds in nonformal education as well, for instance as counselors or instructors at summer camps. They reported that those early experiences as young educators pushed them to choose teaching careers (Wizel, 2018) and continue to serve them in the formal system. One goal of the current research was to explore bridges that educators build while using values, skills, and knowledge and applying methods from nonformal pedagogy in the formal education setting, schools, and classrooms.

\subsection{Research goal}

This study aims a magnifying glass on the opportunities that can happen when educators who are experienced in nonformal settings continue their career paths into the formal education system, becoming teachers and principals of schools. The research goal was to explore qualities and practices from the youth movements that can be brought successfully into the formal education system.

\section{Methods}

This qualitative study, which explores such educators, is part of a research collection conducted for the Council of Youth Movements (a registered nonprofit association), which is the umbrella organization for all the youth movements in Israel. Ten educators were recruited through social media, all had employment experience of 2 to 15 years in youth movements and currently worked in the $\mathrm{K}-12$ public education system in Israel. Seven participants worked as teachers, and three as school principals. The participants were diverse in terms of which youth movement they had attended or led, their years of experience, and the formal school subjects they taught. I interviewed (and recorded) participants at their schools for approximately one hour each. I then transcribed the interview recordings and used those transcriptions in a qualitative coding process. Participants often described the interview process as a reflective one that helped them understand their educational backgrounds, motives, and practices.

\section{Discussion}

Several themes emerged from the qualitative coding of the interviews. In this short paper, I discuss three themes related to differences between nonformal and formal education and the pedagogical bridges educators created in their actions. These themes related to voluntarism, the classroom as a social group, and relationships and dialogue. 


\subsection{Bridge 1: Voluntarism}

Kahane (1997) described voluntarism as a relatively constraint-free pattern of choice (of goals, means, and affiliations) in which the cost of changing one's mind is minimal. This was the main difference between nonformal and formal education systems that participants described. Simply stated, students are required to attend school, but they can choose whether to attend, which, and their level of engagement with a youth movement. One participant described that in the nonformal youth movement, "I spoke enthusiastically with 200 teenagers, and they all listened. Here [formal school], I enter a class of 30 sixth graders, and I need to fight with them regarding everything."

Participants connected this issue of choice in schools with other challenges, such as discipline, motivation, self-efficacy, student engagement, and self-directed learning. Some attempted to enhance choice in their classrooms, in what can be termed instructional choice. That is, these educators made efforts to give learners autonomy to choose among age- or ability-appropriate options, for example, choosing between tasks or selecting a topic for assignments. One teacher described giving choices for a final project by allowing learners to write a paper, record a podcast, or film a videoclip, as well as to choose between independent or small-team work.

Encouraging more choice must be done thoughtfully: It needs to be relevant to the learners and their strategies and ability to choose (Beymer \& Thomson, 2015). The choice must be managed (Katz \& Assor, 2007). For example, because it is difficult-sometimes intimidating - to choose among endless possibilities, the choice can be managed by offering fewer options. In addition, social, cultural, and personal differences regarding choice must be carefully considered. Finally, the conversation about choice for students at the class or school level must consider aspects of teachers' choice, as well.

\subsection{Bridge 2: The classroom as a social group}

Is any group of students a social group? In nonformal pedagogy, learning occurs in a group and involves a social context. Development of the individual connects with development of the group (Silberman-Keller, 2003): the individuals develop inside the group, and the group develops due to the development of the individuals. Unsurprisingly, study participants raised this issue. They discussed how, in nonformal pedagogy, the concept of the group is central; becoming part of a like-minded peer group emerged as a main attraction for youth to join youth movements. This social element allows reciprocal relationships and opportunities to experiment with behaviors and values. The group is perceived as an educational resource and functions like a family and community.

Raviv (2016) offered a relevant distinction between content and process, explaining that content relates to the "what"-academic goals such as the topic or the subject and learning new knowledge. He defined process as the "how," which mostly goes unrevealed. It includes processes that appear in the social group, such as the phases the group goes through, and personal and interpersonal processes, such as group conflicts and dynamics.

Similarly, teachers and principals who have a background in nonformal educational settings stressed their crucial role in leading a dynamic group. They highlighted the broader meaning of teachers' roles, including maintaining relationships, organizational culture, and group norms. They described these as teaching skills to address and give time and energy to things that happen in the peer group. One participating teacher stated that this is his expertise: "I make a circle. We sit in a circle and talk and discuss." Some participants expressed tension in the formal education setting between what teachers must accomplish according to the curriculum and study plan and what is happening right now in the classroom and needs attention.

This prioritization relates to the nonformal term, situated learning, reacting to the current situation as a learning opportunity and being adaptive and flexible. One teacher described, "If kids come back from recess and are occupied with the conflict that was raised, I acknowledge this conflict, and I devote time to it even if I know I have a teaching goal." This time dedicated to social interactions also relates to social-emotional learning. To benefit from the advantages of the class as a group, teachers should prioritize transforming the classroom into a group and encourage learning that involves social interactions. Educational systems, at the same time, need to structure more time so that educators will not need to face the tension between curriculum and social aspects. They then could use the social group to promote both learning and emotional health.

\subsection{Bridge 3: Relationships and dialogue}

One characteristic of a nonformal educational setting is symmetry in personal relationships (Kahane, 1997). "Symmetry, in reference to a relationship, is based on three interrelated elements: actors, who have fairly equivalent resources; exchanges which are balanced reciprocally; and, therefore, expectations which the actors tend mutually to accommodate" (Bekerman \& Keller, 2004, p. 6). Symmetry is about relationships that have more equality and less one-sided power than often seen in formal educational settings. In youth movements, even more key than acquiring knowledge and skills is the 
relationship with the young group-leader educator (often only 2 to 3 years older than the peer members). This leader is a meaningful adult with close bonds to the group members. The leader finds the balance between having authority and friendly relationships and easily learns to move between those roles in a flexible, adaptive manner. The counselors' authority in youth movements is based on eye-level communication. Another important term is dialogue - an educational conversation that includes trust, honesty, and openness from all involved. Freire's (1970) educational philosophy stressed the vital role of dialogue and called for cancellation of the distinction between a teacher and his or her students.

Research participants with nonformal backgrounds were skilled in creating interpersonal dialogue connections with students. They perceived the dialogue as central to other aspects. One teacher said, "We are partners in this. Tell me what you want, what you dream, what you care about, what you're passionate about, and we will structure our learning around this." Another teacher used the term intimacy. She stated that it was hard for her to reach the same level of intimacy with students as she had in nonformal settings due to her lack of time and the large number of students in her classroom.

Just as the other bridges interconnected, this bridge connects to changes in the teachers' rolefrom one of being the source of knowledge to one of an adult who, through conversation and communication, supports and facilitates learning and development.

Educators found creative ways to invest in personal relationships, often during recess times, while structuring independent work, or when incorporating meeting times during classes. A school principal gave an excellent example of how she uses existing organizational structures to promote communication: "If there is a conversation in my room with the guidance counselor and a few adults from the team and the student, I will ask the student to summarize the conversation. This way, I can learn what he heard, what we meant, and what the gaps are."

\subsection{Other bridges}

Other bridges arose in the research but are only summarized here because they are beyond the scope of this short paper. One such theme regarded flexibly in using diverse teaching methods-games, group work, outdoor learning, and other practices that serve the learning goals - and other priorities, such as the group. In general, it seemed that educators with nonformal educational backgrounds tended to use progressive teaching methods that also required a shift in their role as teachers.

Another bridge related to developing self-directed learners. This relevant challenge received particular attention during the COVID-19 pandemic. Participants shared the ways in which they gave students more responsibility and successfully enhanced their engagement. One straightforward method was to do less as adults and authentically trust the students to do their share. This challenge also related to choice and the ability to take risks and fail in a blame-free environment with trust and confidence.

A third theme regarded the world outside the school. Teachers used the curriculum as a platform to address social justice issues and to encourage discussions of values and activism, making their education actions relevant and significant.

\section{Conclusion: Questions and vision}

The formal education system desires to develop students' 21 st-century skills. Nonformal educational settings such as clubs, sports groups, and, in the case of this study, youth movements successfully address those skills. Despite the differences between settings, educators have ways to carry some nonformal pedagogy into the formal education system. Those teaching methods support students to develop as self-directed learners and address students' social-emotional needs by envisioning the classroom as a social group and fostering dialogue and eye-level relationships.

What can formal settings do to help this entrance of nonformal pedagogy into schools? Schools can accept more teachers with nonformal backgrounds and encourage these educators to transfer the skills they learned in nonformal setting into the school. One study participant described taking 3 years to understand that it was allowed and acceptable for her to play games with her students, as she had in the youth movement. Schools can recognize behaviors and habits connected to nonformal pedagogies and encourage all teachers, regardless of their backgrounds, to adopt appropriate methods and ways of working. In addition, they must address obstacles to doing so, such as the classroom size or the school-day structure.

The formal education system is often described as strict. However, in this study, I experienced the system's elasticity and witnessed many educators lead nonformal-style education inside the formal education system: teachers who continually adapted their teaching and had meaningful personal connections with their students, and school leaders who led an organizational culture devoted to creating open communication that then transfers to students. These practices are not in themselves innovative; their value is in their authenticity as educators use them to bridge the life experiences and perspectives necessary for 21 st-century schooling. Those efforts encourage new ways to look at what we already know and answer the call for more bridges than walls. 


\section{References}

Bekerman, Z., \& Keller, D. S. (2004). Non-formal pedagogy epistemology rhetoric and practice. Education and Society, 22, 45-65.

Beymer, P. N., \& Thomson, M. M. (2015). Effects of choice in the classroom. Support for Learning, 30, $105-120$.

Cohen, E. H. (2015). Changes among Israeli youth movements: A structural analysis based on Kahane's code of informality. Cambridge Journal of Education, 45, 223-243.

Freire, P. (1970). Pedagogy of the oppressed. New York: Seabury.

Kahane, R. (1997). The origins of postmodern youth: Informal youth movements in a comparative perspective. New York: Walter de Gruyter.

Katz, I., \& Assor, A. (2007). When choice motivates and when it does not. Educational Psychology Review, $19,429-442$.

Michaeli, N. (2013). There is a different education already. Hed Hchinuch, 5, 78-79.

Organisation for Economic Co-operation and Development. (2018). The future of education and skills: Education 2030. https://www.oecd.org/education/2030/E2030\%20Position\%20Paper\%20 (05.04.2018).pdf

Raviv, A. (2016). Content and process: Working with groups in the nonformal education. Oranim College, Israel.

Shmida, M., \& Romi, S. (2008). Non-formal education in changing reality. Hebrew University Magnes Press.

Silberman-Keller, D. (2003). Toward the characterization of non-formal pedagogy. Paper presented at the Annual Meeting of the American Educational Research Association, Chicago, IL.

Smith, M. K. (2002). Informal, non-formal and formal education: A brief overview of different approaches. Encyclopedia of informal education. https://infed.org/mobi/informal-non-formal-and-formaleducation-a-brief-overview-of-some-different-approaches/

Wizel, M. (2018). Preparing educational hackers. In Y. Weinberger and Z. Libman (Eds.), Contemporary pedagogies in teacher education and development (pp. 101-118). London: IntechOpen. 